\title{
Identification and extraction method of quercetin from flesh and skin of shallot (Allium ascalonicum) cultivated in Soc Trang province, Vietnam
}

\author{
${ }^{1, *}$ Thuy, N.M, ${ }^{1,2}$ Tuyen, N.T.M, ${ }^{1,2}$ Cuong, N.P., ${ }^{1}$ Huyen, L.T.N, ${ }^{1}$ Phuong, N.P, \\ ${ }^{1}$ Nguyen, L.T.T, ${ }^{2}$ Kim, J.H., ${ }^{1}$ Thu N.T. and ${ }^{1}$ Tai, N.V. \\ ${ }^{1}$ College of Agriculture, Can Tho University, Can Tho city, Vietnam \\ ${ }^{2}$ Chungnam National University, Yuseong, Daejeon, South Korea
}

\begin{abstract}
Article history:
Received: 29 August 2019

Received in revised form: 1 October 2019

Accepted: 3 October 2019

Available Online: 10 October 2019
\end{abstract}

\section{Keywords:}

Quercetin,

Derivatives,

Ultrasound-assisted

extraction,

Extraction yield.

\section{DOI:}

https://doi.org/10.26656/fr.2017.4(2).306

\begin{abstract}
Quercetin is a bioactive compound that has many beneficial effects on human health. Due to a lack of information about quercetin and quercetin derivatives in the Vietnam shallot, this work aimed to identify the quercetin family in shallot skin and flesh by liquid chromatography-mass spectrometry. Effect of extraction method (conventional solvent extraction and ultrasound-assisted extraction), including ethanol concentration (40-80\%) and extraction time (15 to 60 mins) on the yield of quercetin were also investigated in this study. Quercetin, quercetin-glucoside and methylated-quercetin-hexose were commonly found in the extract of shallot flesh and skin. A very small amount of quercetin aglycone $(0.7 \%)$ was found in flesh extract, while it was the most abundant in the skin sample (46.3\%). The high content of quercetin-mono-glycoside was obtained in shallot extract (43.8\% and $35.3 \%$ in the shallot flesh and skin, respectively). The flesh extract also contained high level of quercetin-di-glucoside (38.9\%). About $14-16 \%$ of methylatedquercetin (-glucoside) were found in shallot bulb (both skin and flesh). It was found that ethanol concentration and extraction time directly affected on the quercetin extraction yield. The highest quercetin content was obtained in the sample which was extracted in $60 \%$ ethanol in combination with ultrasound-assisted extraction for 15 to 45 mins. The ultrasound-assisted extraction method improved quercetin yield by $13.38-15.64 \%$ and 49.46-56.88\% for shallot skin and flesh compared to conventional solvent extraction. This study proved that ultrasound-assisted extraction could successfully be used for extraction of quercetin from shallot (both skin and flesh).
\end{abstract}

\section{Introduction}

Shallot (Allium ascalonicum) commonly used in many Asian diets for thousands of years. It has been used in both culinary purposes and therapeutic benefits. In Vietnam, shallot was cultivated in Soc Trang province for over hundred years. Grown in specific weather conditions, the shallots have a specific shade of red, equal segments and special taste. Shallot contains high amounts of bioactive compounds such as organo-sulphur compounds, polyphenols and selenium (Leelarungrayub et al., 2006) and considerable amounts of flavonoids (Zhao et al., 2007). The high concentration of quercetin in shallot was also reported (Nair et al., 2002).

Different bound forms of quercetin, including sugar, phenolic acid and alcohol, were found in the plant materials (Walle, 2004; Wiczkowski and Piskuła, 2004). In food, most of quercetin conjugated to sugar molecules by glycosidic linkage (Kaşıkcı et al., 2016). There were
5 quercetin derivatives that were found in flesh and skin of shallot extract (quercetin-3,4'-O-bis- $\beta$-glucoside, quercetin-3- $O$ - $\beta$-glucoside, quercetin- $4^{\prime}-O$ - $\beta$-glucoside, isorhamnetin- $4^{\prime}-O-\beta$-glucoside, and quercetin aglycone (Wiczkowski et al., 2008). It was reported that $83 \%$ of total quercetinin a free form was found in the dried skin, whereas the major form of quercetin in shallot flesh was quercetin glucosides ( $>99 \%$ ), mainly by quercetin- $3,4^{\prime}-O$ -bis-b-glucoside and quercetin-4'-O-b-glucoside. The number of sugar molecule that attached to quercetin strongly impacted on the polarity and molecule size, resulting in difference its bioavailability (Lee and Mitchell, 2012). Pure quercetin had low solubility in water (Rothwell et al., 2005), the glycosidic linkage was broken in the small intestine and releasing the quercetinaglycone. The absorption rate of quercetin aglycone by passive absorption was reported from 65 to $81 \%$ (Walle et al., 2000). However, a great bioavailability of quercetin-monoglucoside from onion 
was observed (Hollman et al., 1995). It was hypothesized that the $\mathrm{Na}^{+}$-dependent glucose cotransporter (SGLT1) was involved in this mechanism (Hollman et al., 1999). Therefore, the structure of quercetin in food was a critical factor in their bioavailability (Materska, 2008; Kaşıkcı et al., 2016).

During the processing of shallots, the outer dried leaves are removed. Shallot skin is a source of phenolic compounds, which has a high content of quercetin and strong antioxidant (Choi et al., 2015). Since the shallot/ onions and their skins are a good source of various bioactive compounds, extraction procedures of quercetin and its glycosides from these plant materials were intensively developed and optimized (Jang et al., 2013; Katsampa et al., 2015).

There are many techniques commonly used for quercetin extraction from plant materials, such as conventional solvent extraction (Wach et al., 2005), ultrasound-assisted extraction (Jang et al., 2013), supercritical fluid extraction (Martino and Guyer, 2004) and microwave-assisted extraction (Kumar et al., 2014). The most suitable solvents are aqueous mixtures containing ethanol, methanol, acetone, and ethyl acetate. Among them, ethanol has been known as a good and safe solvent for polyphenol extraction and for human consumption.

The main benefits of an ultrasound-assisted extract are the breakdown of the cell wall leading to effective solvent extraction. Recently, ultrasound-assisted extraction (UAE) was an emerging technology which effectively improved extraction yield in shorter extraction time. So far, studies on the quercetin family and extraction method from flesh and skin of shallot cultivated in Vietnam are still limited. Here to, the objective of the current research was to identify quercetin from flesh and skin of shallot cultivated in Soc Trang province, Vietnam. In this study, both conventional and ultrasound-assisted extraction technologies were applied in order to investigate the effect of two extraction methods on aqueous ethanol extraction of quercetin compounds.

\section{Materials and methods}

\subsection{Sample collection and preparation}

The shallots were harvested from Vinh Chau town, Soc Trang province, Vietnam.

The shallot bulbs usually take around 60-65 days to mature. The shallot bulb harvest should begin when the greens of the plant start to wither, fall over and die. They will turn brown and become droopy while the bulbs will protrude from the soil and the outer skin becomes papery. This usually happens in mid to late summer. After harvesting, the bulbs are dried out some in the garden for about a week or so, weather permitting and then store them in mesh bags in a cool and dry location. The bulbs were washed with clean water, skin removed and ozone treatment of $3 \mathrm{ppm}$ in 5 mins. Then, the shallots were sliced and dried at a temperature of $60^{\circ} \mathrm{C}$ until $6-8 \%$ moisture content is reached

The shallot skin was obtained from the processing of shallot products. After collection, the skin was washed under tap water and ozone treatment (3 ppm) in 5 mins. Then, the shallot skin dried at a temperature of $60^{\circ} \mathrm{C}$ until reaching $6-8 \%$ of moisture. All samples (shallot flesh/skin) were stored in a sealed $\mathrm{PE}$ bag at the temperature of $0-3^{\circ} \mathrm{C}$ under the subdued light.

\subsection{Conventional solvent extraction (CSE) and Ultrasound-assisted extraction (UAE)}

The ratio of raw materials (shallot flesh/skin) to solvent is 1:10 (w/v). The dried material (15 g) was used for each treatment.

There are two factors affect the CSE and UAE efficacy: the concentration of ethanol solution (from 50 to $80 \%$ ) and the time of extraction (from 15 to $60 \mathrm{mins}$ ). The process of extraction began by mixing $15 \mathrm{~g}$ of dried shallot flesh/skins in $150 \mathrm{~mL}$ of ethanol solution. The temperature of the sample was maintained in the water bath (Memmer, USA) (for CSE) or ultrasonic bath (490 $\mathrm{W}, 42 \mathrm{kHz}$, USA) (for UAE) at $60^{\circ} \mathrm{C}$ for different extraction time as mentioned above. Thereafter, centrifugation was applied using a centrifuge $(\mathrm{Z} 232 \mathrm{~K}$, Hermle, Germany) with 12,000 rpm for $30 \mathrm{mins}$ at room temperature $\left(25^{\circ} \mathrm{C}\right)$. Subsequently, the centrifuged clear liquid was obtained and kept in dark condition at low temperature $\left(2-3^{\circ} \mathrm{C}\right)$ until further analysis of quercetin. Each treatment was performed three times.

\subsection{Quercetin analysis}

\subsubsection{Sample preparation}

Shallot extract $(0.2 \mathrm{~mL})$ was centrifuged (3 mins, $15,000 \mathrm{rpm})$ to remove the solid substance. Then, the sample was purified by protein precipitation and solidphase extraction (Sep-Pak, $200 \mathrm{mg}$ C18 Cartridge, Water, USA). Briefly, the cartridge was activated by methanol and conditioned by distilled water. Then sample was loaded sample through the cartridge and followed by de-salting with distilled water. Finally, the analytes were eluted with $60 \%$ methanol.

\subsubsection{Quercetin analysis by UPLC/UV/MS}

The quercetin and its derivatives were determined by positive mode of LC-ESI-QQQ (6460 Triple Quadrupole 
System, Agilent, USA) coupled with a UV detector (1260 Infinity, Agilent, USA). Separations of quercetin glucosides and quercetin aglycone were performed on analytical column Zorbaz Eclipse C18 $(2.1 \times 50 \mathrm{~mm}, 1.8$ $\mu \mathrm{m}$, Agilent, USA). The mobile phase consisted of water (solvent A) and acetonitrile (solvent B) each containing $0.1 \%$ formic acid. The flow rate was $0.4 \mathrm{~mL} / \mathrm{min}$ and the gradients between the time points were as follows: $0-4$ mins, 5-15\%B; 4-7 mins, $15-55 \% \mathrm{~B}$; 7-9 mins, 55-90\%B; 9-12 mins 90\%B; 13-18 min, 5\%B. The UV detection wavelength was set at $370 \mathrm{~nm}$ (the maximum absorption wavelength of quercetin). The MS conditions were as follow: gas temperature, $250^{\circ} \mathrm{C}$; gas flow, $8 \mathrm{~L} / \mathrm{min}$; Nebulizer, $45 \mathrm{psi}$; sheath gas temperature, $300^{\circ} \mathrm{C}$; sheath gas flow: $12 \mathrm{~L} / \mathrm{min}$; capillary: $3500 \mathrm{~V}$ (positive), $2500 \mathrm{~V}$ (negative); Nozzle voltage: $500 \mathrm{~V}$ (positive), $500 \mathrm{~V}$ (negative); and scan mass: 200-800 (m/z) (positive).

\subsection{Data analysis}

Mass spectrometry data was analysed by Mass Hunter software (B.07.00). The distribution of quercetin and its derivatives were calculated from the relative abundance of each compound. If the compound had isomers, the relative abundance was calculated as the total area of the isomer structures. The experiment was performed in triplicated. The statistical significance was calculated and confirmed by analysis of variance (ANOVA) using STATGRAPHICS Centurion XVII.
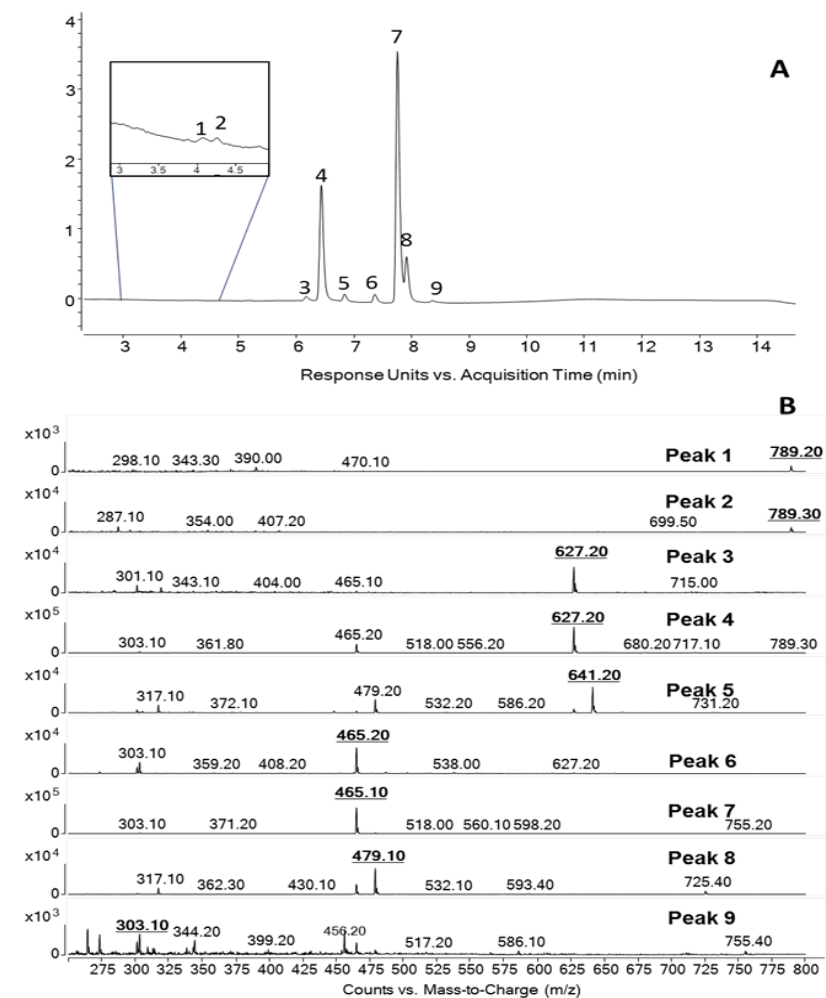

Figure 1. UV chromatogram (at $370 \mathrm{~nm}$ ) of shallot flesh extract with annotation (A); mass spectra of quercetin and derivatives which were annotated in the UV chromatogram (B)

\section{Results and discussion}

3.1 Quercetin and its derivative in the flesh and skin of shallot

In the combination of UV absorption at 370nm and mass spectrum by EIC/MS, quercetin and its derivatives were found in the extract of shallot flesh and skin ( 9 and 7 compounds, respectively). They are quercetin, quercetin-glucoside and methylated-quercetin-hexose. The UV chromatogram and mass spectra these compounds were shown in Figure 1 and Figure 2. Table 1 summarizes the detected compounds, corresponding to the retention time and annotation in Figures 1 and 2 . Interestingly, quercetin-tri-hexose ( 2 isomers) was found only in the flesh of shallot and but not in its skin. And, methylate-quercetin occurred in the skin of shallot. Quercetin aglycone, methylate-quercetin-glucoside (diand mono-) were found in both flesh and skin samples. In the flesh extract, both quercetin di-glucoside and quercetin mono-glucoside had two isomers. Meanwhile, there was only one quercetin-mono-glucoside compound in the skin extract.

Distribution of quercetin and quercetin derivatives in flesh and skin was also compared. UV chromatograms and distribution of quercetin family in the flesh and skin samples were showed in Figures 3 and 4. The UV chromatogram clearly showed a significant difference of quercetin alycone intensity in the skin compared to it in the flesh sample. A tiny amount of quercetin alycone $(0.7 \%)$ was found in flesh extract, while it was the most
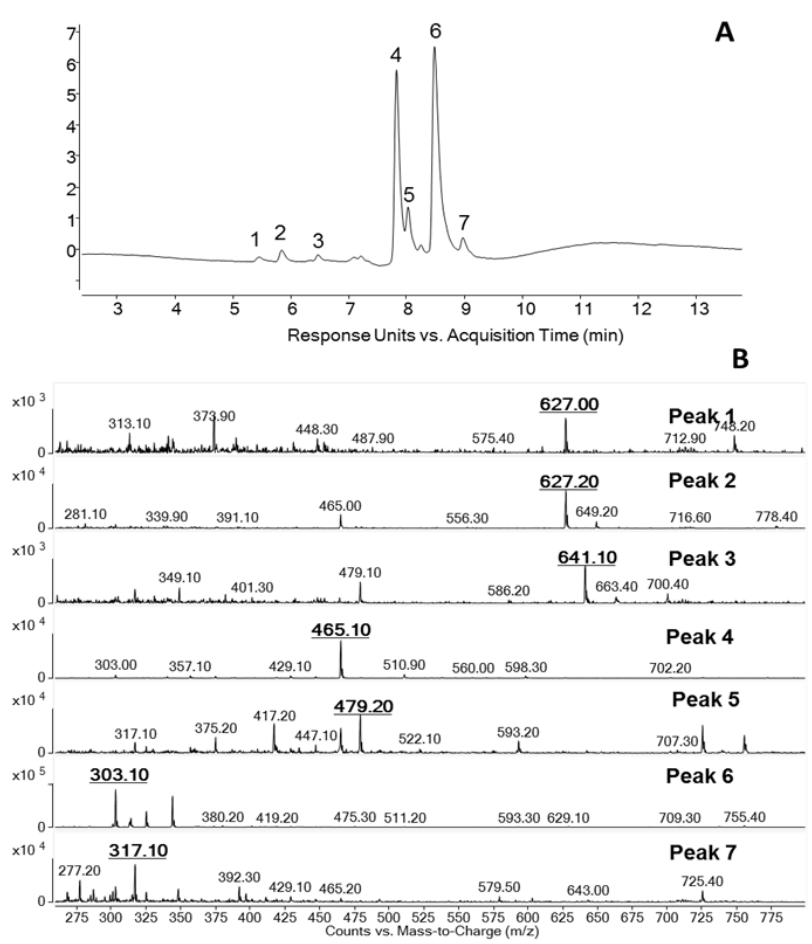

Figure 2. UV chromatogram (at $370 \mathrm{~nm}$ ) of shallot skin extract with annotation (A); mass spectra of quercetin and derivatives which were annotated in the UV chromatogram (B).

(C) 2019 The Authors. Published by Rynnye Lyan Resources 
Table 1. Quercetin composition in shallot extract

\begin{tabular}{ccccl}
\hline Sample & Annotation & $\mathrm{RT}(\mathrm{min})$ & $\mathrm{m} / \mathrm{z}\left(\mathrm{M}+\mathrm{H}^{+}\right)$ & \multicolumn{1}{c}{ Compound } \\
\hline & 1 & 4.21 & 789.3 & Quercetin-tri-glucoside \\
& 2 & 4.36 & 789.2 & Quercetin-tri-glucoside \\
Shallot & 3 & 5.27 & 627.2 & Quercetin-di-glucoside \\
flesh & 5 & 6.535 & 627.2 & Quercetin-di-glucoside \\
& 6 & 6.939 & 641.2 & Methylated-quercetin-di-glucoside \\
& 7 & 7.467 & 465.1 & Quercetin-mono-glucoside \\
& 8 & 7.87 & 465.1 & Quercetin-mono-glucoside \\
& 9 & 8.019 & 479.2 & Methylated quercetin-mono-glucoside \\
Shallot & 1 & 5.365 & 627.2 & Quercetin-di-glucoside \\
skin & 2 & 6.535 & 627.2 & Quercetin-di-glucoside \\
& 3 & 6.938 & 641.1 & Methylated-quercetin-di-glucoside \\
& 4 & 7.85 & 465.1 & Quercetin-mono-glucoside \\
& 5 & 7.923 & 479.2 & Methylated quercetin-mono-glucoside \\
& 6 & 8.406 & 303.1 & Quercetin \\
\hline
\end{tabular}

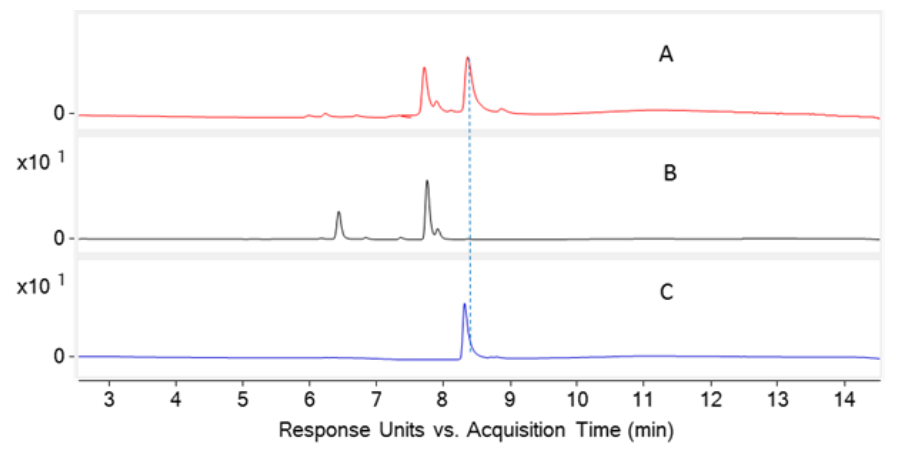

Figure 3. UV chromatogram of shallot skin extract (A); shallot bulb extract (B) and quercetin standard (C)
A
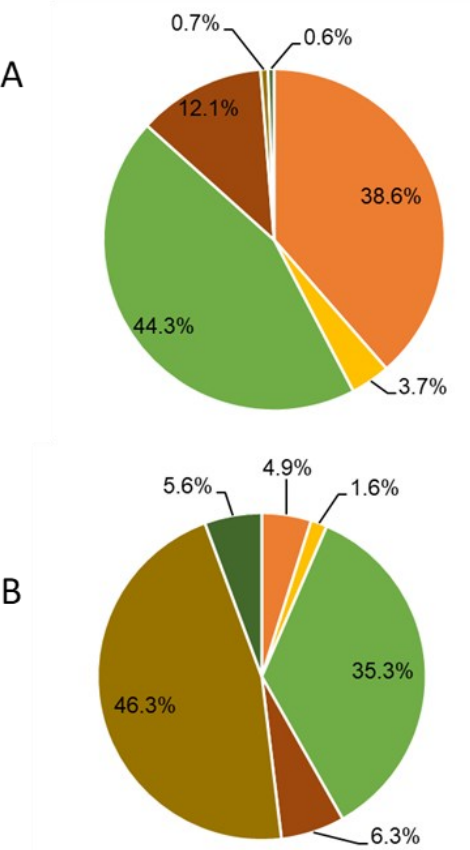

Shallot bulb

- Quercetin-di-glucoside

- Methylated-quercetin-di-glucoside

- Methylated-mono-glucoside

= Quercetin

- Quercetin-tri-glucoside

Shallot skin

- Quercetin-di-glucoside

Methylated-quercetin-di-glucoside

- Quercetin-mono-glucoside

- Methylated-mono-glucoside

Quercetin

- Methylated-quercetin
- Quercetin-mono-glucoside

Figure 4. Distribution of quercetin and quercetin derivatives in shallot flesh extract (A); shallot skin extract (B)

abundant in the skin sample (46.3\%). Quercetin-monoglycoside usually occurred in high amount in shallot extract that accounted for $43.8 \%$ and $35.3 \%$ in the flesh and skin samples. The flesh extract also contained great level of quercetin-di-glucoside (38.9\%). In addition, about $14-16 \%$ of methylate-quercetin (-glucoside) were found in both kinds of sample. In this study, the Vietnamese shallot flesh extract contains quercetin mainly in form glucosides (only $0.7 \%$ in aglycone form). It was found in previous study that the Poland shallot flesh extract contained quercetin glucosides of $99.2 \%$ (Wiczkowski et al., 2008). In Vietnamese shallot, the glucoside forms can be mono-, di and tri-glucosides. The composition of Poland and Italian shallots were reported to contained quercetin, isorhamnetin (a methylatedquercetin) and their derivatives, including mono- and diglucoside (Wiczkowski et al., 2008; Fattorusso et al., 2002). Quercetin-tri-glucoside was found sometime in the red onion flesh at low level (Bonaccorsi et al., 2005). The skin of shallot was found to have a high ratio of quercetin aglycone (46\%). It was reported that the quercetin aglycone content was different by layers and increased from inside to outside (Lee and Mitchell, 2011). Our data showed that the ratio of quercetin aglycone in Vietnam shallot skin was lower than that in Poland shallot (83\%) (Wiczkowski et al., 2008). In addition, the content and composition of quercetin compounds were also affected by storage conditions such as light exposure (Ko et al., 2015).

\subsection{Effect of different extraction conditions on total quercetin yield from shallot flesh and skin}

\subsubsection{Effect of ethanol concentration}

Recent studies reported that the type of solvent had extensively impact on the extraction efficiency of phytochemicals such as flavonoid and total phenolic compounds (Do et al., 2014). Yan et al. (2015) indicated that ethanol was effective for isolation of phenols and flavonoids. In our study, the effect of different ethanol concentrations ( 40 to $80 \%$ ), extraction methods and time on the yielding of shallot flesh/skin were assessed (Table 2 and 3). It was observed that the percentage of quercetin 
Table 2. Quercetin content of shallot skin by different ethanol concentration, time and methods of extractions

\begin{tabular}{ccccc}
\hline \multirow{2}{*}{ Sample code } & $\begin{array}{c}\text { Ethanol concentration }(\%) \\
\text { - Time extraction (min) }\end{array}$ & \multicolumn{2}{c}{ Extraction methods } & Additional \% of quercetin \\
\cline { 3 - 4 } M1 & $50-15$ & $2.769^{* \mathrm{a}}$ & $3.145^{\mathrm{a}}$ & 13.58 \\
by UAE compared to CSE
\end{tabular}

Table 3. Quercetin content of shallot flesh by different ethanol concentration, time and methods of extractions

\begin{tabular}{|c|c|c|c|c|}
\hline \multirow{2}{*}{$\begin{array}{l}\text { Sample } \\
\text { code }\end{array}$} & \multirow{2}{*}{$\begin{array}{l}\text { Ethanol concentration }(\%)- \\
\text { Time extraction (min) }\end{array}$} & \multicolumn{2}{|c|}{ Extraction methods } & \multirow{2}{*}{$\begin{array}{l}\text { Additional } \% \text { of quercetin by } \\
\text { UAE compared to CSE }\end{array}$} \\
\hline & & CSE & UAE & \\
\hline M1 & $50-15$ & $0.740^{* \mathrm{a}}$ & $1.106^{\mathrm{a}}$ & 49.46 \\
\hline M2 & $50-30$ & $0.775^{\mathrm{abc}}$ & $1.186^{\mathrm{b}}$ & 53.03 \\
\hline M3 & $50-45$ & $0.794^{\text {bcde }}$ & $1.204^{\mathrm{bcd}}$ & 51.64 \\
\hline M4 & $50-60$ & $0.799^{\text {bcdef }}$ & $1.210^{\mathrm{bcd}}$ & 51.44 \\
\hline M5 & $60-15$ & $0.789^{\mathrm{bcd}}$ & $1.212^{\mathrm{bcd}}$ & 53.61 \\
\hline M6 & $60-30$ & $0.814^{\text {cdef }}$ & $1.253^{\mathrm{def}}$ & 53.93 \\
\hline M7 & $60-45$ & $0.833^{\mathrm{ef}}$ & $1.296^{\mathrm{f}}$ & 55.58 \\
\hline M8 & $60-60$ & $0.825^{\text {def }}$ & $1.288^{\mathrm{ef}}$ & 56.12 \\
\hline M9 & $70-15$ & $0.826^{\mathrm{def}}$ & $1.267^{\mathrm{ef}}$ & 53.39 \\
\hline M10 & $70-30$ & $0.828^{\text {def }}$ & $1.278^{\mathrm{ef}}$ & 54.35 \\
\hline M11 & $70-45$ & $0.835^{\mathrm{f}}$ & $1.275^{\mathrm{ef}}$ & 52.69 \\
\hline M12 & $70-60$ & $0.814^{\text {cdef }}$ & $1.243^{\text {cde }}$ & 52.7 \\
\hline M13 & $80-15$ & $0.767^{\mathrm{ab}}$ & $1.193^{b c}$ & 55.54 \\
\hline M14 & $80-30$ & $0.821^{\mathrm{def}}$ & $1.288^{\mathrm{ef}}$ & 56.88 \\
\hline M15 & $80-45$ & $0.822^{\mathrm{def}}$ & $1.267^{\mathrm{ef}}$ & 54.14 \\
\hline M16 & $80-60$ & $0.809^{\text {cdef }}$ & $1.242^{\text {cde }}$ & 53.52 \\
\hline
\end{tabular}

Note: *Average data of three replications

Mean values followed by the different letters (a-g) superscript within each column are significantly different at $\mathrm{P}<0.05$

in shallot flesh is less than in skin. According to Hirota et al. (1999), quercetin was found at the high concentration in the outer layer in compared to the inner layer. Since the aged cell located in the outer layer coincided with the accumulation of quercetin aglycone due to the enzymatic hydrolysis of quercetin glycosides. Lee and Mitchell (2011) also reported that the highest of quercetin aglycone content occurred in the outer most layers of all varieties of onions.

The ethanol concentration was also affected the quercetin content (in both shallot flesh and skin). It was found that the quercetin content of the extracts decreased with decreasing ethanol content. The quercetin content of the $60 \%$ aqueous ethanol extract is highest in comparison to others. However, the high content of ethanol (from 70 to $80 \%$ ) did not significantly increase the content of quercetin in the extract. This is consistent with some previous reports. Horbowicz (2002) reported that the highest yield of quercetin from powdered dry scales of onion was obtained by hot extraction with $60 \%$ ethanol. Jang et al. (2013) also reported that the ethanol concentration (40-80\%) and extraction temperature (40$60^{\circ} \mathrm{C}$ ) had a tremendous effect on the quercetin yield. Under the optimal extraction temperature of $49^{\circ} \mathrm{C}$ using $59 \%$ ethanol, the quercetin yield was found to be 11.08 $\mathrm{g} / \mathrm{kg}$ with the solid waste of onion. However, Savic et al. (2016) optimized an extraction procedure of quercetin from green tea and found that ethanol concentration had a significant effect on the change in the quercetin amount in the extract, the quercetin yield significantly increased when concentrations were higher than $80 \%(\mathrm{v} / \mathrm{v})$. It may be due to the different levels of quercetin in the different 
kinds of vegetables.

\subsubsection{The effect of extraction methods}

It was observed that UAE represented an enhancement in the quercetin extraction yield compared to conventional extraction methods. The results showed that UAE showed a higher yield for shallot skin and flesh extract, while conventional extraction gave the lower value. The extraction yield increased 13.38 to $15.64 \%$ by UAE from shallot skin (as mentioned in Table 2) and 49.46 to $56.88 \%$ from shallot flesh (as mentioned in Table 3) in comparison to CSE in the same extraction conditions. Our results are consistent with earlier research. Nam et al. (2015) indicated that the higher yields of phenolic compounds were obtained only by ultrasound-assisted and supercritical extractions. The ideal conditions for total phenolic compounds extraction from peach were performed at $41.53^{\circ} \mathrm{C}, 43.99 \%$ of power for $27.86 \mathrm{~min}$ (Altemimi et al., 2016).

It was indicated that extraction efficiency by the UAE was considerably greater than those using only solvent. The recovery of phenolic compounds from purple potatoes by UAE increased $22 \%$ compared to accelerated-solvent extraction (Cai et al., 2016). Similarly, a study on olefinic leaves showed that the phenolic compound productivity by UAE was almost 2 fold more than it in conventional extraction (47 and 27 mg GAE/g DW, respectively) (Medina-Torres et al., 2017). Particularly, an increase of $74 \%$ of chlorogenic acid, a mainly phenolic compound, was also found in this study. Jin et al. (2011) proposed that ultrasound treatment showed increasing yield of quercetin in proportion to the power and the time. The highest yield of quercetin $(4.09 \pm 0.29 \mathrm{mg} / \mathrm{g})$ was obtained under UAE at $606.4 \mathrm{~W}$ for $21.7 \mathrm{mins}$, in combined to $43.8 \%$ ethanol.

The quercetin content in the extract increased with the longer extraction time.The highest quercetin yield was noticed for the extraction times longer than $35 \mathrm{~min}$ using ethanol concentrations higher than $60 \%$. Our obtained result was consistent with Muñiz-Márquez et al. (2013), in which the extracted phenolic content from lyophilized Laurus nobilis L. surged with prolonging extraction time. Improvement of total phenol extraction efficiency by UAE was observed in increasing extraction time from10 to 27.89 mins (Altemimi et al., 2016). To optimize the procedure of UAE of quercetin from the solid waste of onion using ethanol solution, Jang et al. (2013) reported that the extraction time (15-35 mins) was little significant.

\section{Conclusion}

An attempt was made to extract quercetin, a potent antioxidant, through solvent and ultrasound-assisted extraction procedures. The quercetin and its derivatives were determined by positive mode of LC-ESI-QQQ coupled with a UV detector. It was obvious that the high yield of quercetin obtained by UAE with ethanol solution $60 \%$ in $30-45$ mins was much higher. UAE is effective, fast and the simple method of extraction of crude quercetin from dry skin and flesh of Vietnamese shallot.

\section{Conflict of Interest}

The authors declare no conflict of interest.

\section{References}

Altemimi, A., Watson, D.G., Choudhary, R., Dasari, M.R. and Lightfoot, D.A. (2016). Ultrasound assisted extraction of phenolic compounds from peaches and pumpkins. PLoS One, 11(2), e0148758. https://doi.org/10.1371/journal.pone.0148758

Bonaccorsi, P., Caristi, C., Gargiulli, C. and Leuzzi, U. (2005). Flavonol glucoside profile of southern Italian red onion (Allium cepa L.). Journal of Agricultural and Food Chemistry, 53(7), 2733-2740. https:// doi.org/10.1021/jf048152r

Cai, Z., Qu, Z., Lan, Y., Zhao, S., Ma, X., Wan, Q. and Li, P. (2016). Conventional, ultrasound-assisted, and accelerated-solvent extractions of anthocyanins from purple sweet potatoes. Food Chemistry, 197(Part A), 266-272. https://doi.org/10.1016/ j.foodchem.2015.10.110

Choi, I.S., Cho, E.J., Moon, J.H. and Bae, H.J. (2015). Onion skin waste as a valorization resource for the by-products quercetin and biosugar. Food Chemistry, 188, 537-542. https://doi.org/10.1016/ j.foodchem.2015.05.028

Do, Q.D., Angkawijaya, A.E., Tran-Nguyen, P.L., Huynh, L.H., Soetaredjo, F.E., Ismadji, S. and Ju, Y.H. (2014). Effect of extraction solvent on total phenol content, total flavonoid content, and antioxidant activity of Limnophilaaromatica. Journal of Food and Drug Analysis, 22(3), 296-302. https://doi.org/10.1016/ j.jfda.2013.11.001

Fattorusso, E., Iorizzi, M., Lanzotti, V. and TaglialatelaScafati, O. (2002). Chemical composition of shallot (Allium ascalonicum Hort.). Journal of Agricultural and Food Chemistry, 50(20), 5686-5690. https:// doi.org/10.1021/jf020396t

Hirota, S., Shimoda, T. and Takahama, U. (1999). Distribution of flavonols and enzymes participating in the metabolism in onion bulbs: mechanism of accumulation of quercetin and its glucosides in the abaxial epidermis. Food Science and Technology 
Research, 5(4), 384-387. https://doi.org/10.3136/ fstr.5.384

Hollman, P.C., de Vries, J.H., van Leeuwen, S.D., Mengelers, M.J. and Katan, M.B. (1995). Absorption of dietary quercetin glycosides and quercetin in healthy ileostomy volunteers. The American Journal of Clinical Nutrition, 62(6), 1276-1282. https:// doi.org/10.1093/ajen/62.6.1276

Hollman, P.C., Bijsman, M.N., van Gameren, Y., Cnossen, E.P., de Vries, J.H. and Katan, M.B. (1999). The sugar moiety is a major determinant of the absorption of dietary flavonoid glycosides in man. Free Radical Research, 31(6), 569-573. https:// doi.org/10.1080/10715769900301141

Horbowicz, M. (2002). Method of quercetin extraction from dry scales of onion. Vegetable Crops Research Bulletin, 57, 119-124.

Jang, M., Asnin, L., Nile, S.H., Keum, Y.S., Kim, H.Y. and Park, S.W. (2013). Ultrasound-assisted extraction of quercetin from onion solid wastes. International Journal of Food Science and Technology, 48(2), 246-252. https://doi.org/10.1111/ j.1365-2621.2012.03180.x

Jin, E.Y., Lim, S., oh Kim, S., Park, Y.S., Jang, J.K., Chung, M.S. and Choi, Y.J. (2011). Optimization of various extraction methods for quercetin from onion skin using response surface methodology. Food Science and Biotechnology, 20(6), 1727-1733. https://doi.org/10.1007/s10068-011-0238-8

Katsampa, P., Valsamedou, E., Grigorakis, S. and Makris, D.P. (2015). A green ultrasound-assisted extraction process for the recovery of antioxidant polyphenols and pigments from onion solid wastes using Box-Behnken experimental design and kinetics. Industrial Crops and Products, 77, 535543. https://doi.org/10.1016/j.indcrop.2015.09.039

Kaşıkc1, M.B. and Bağdatlığlu, N. (2016). Bioavailability of quercetin. Current Research in Nutrition and Food Science Journal, 4(Special Issue Nutrition in Conference October 2016), 146-151. https://doi.org/10.12944/CRNFSJ.4.Special-IssueOctober.20

Ko, E.Y., Nile, S.H., Sharma, K., Li, G.H. and Park, S.W. (2015). Effect of different exposed lights on quercetin and quercetin glucoside content in onion (Allium cepa L.). Saudi Journal of Biological Sciences, 22(4), 398-403. https://doi.org/10.1016/ j.sjbs.2014.11.012

Kumar, B., Smita, K., Kumar, B., Cumbal, L. and Rosero, G. (2014). Microwave-assisted extraction and solid-phase separation of quercetin from solid onion (Allium cepa L.). Separation Science and
Technology, 49(16), 2502-2509.

https:// doi.org/10.1080/01496395.2014.933982

Lee, J. and Mitchell, A.E. (2012). Pharmacokinetics of quercetin absorption from apples and onions in healthy humans. Journal of Agricultural and Food Chemistry, 60(15), 3874-3881. https:// doi.org/10.1021/jf3001857

Lee, J. and Mitchell, A.E. (2011). Quercetin and isorhamnetin glycosides in onion (Allium cepa L.): varietal comparison, physical distribution, coproduct evaluation, and long-term storage stability. Journal of Agricultural and Food Chemistry, 59(3), 857-863. https://doi.org/10.1021/jf1033587

Leelarungrayub, N., Rattanapanone, V., Chanarat, N. and Gebicki, J.M. (2006). Quantitative evaluation of the antioxidant properties of garlic and shallot preparations. Nutrition, 22(3), 266-274. https:// doi.org/10.1016/j.nut.2005.05.010

Martino, K.G. and Guyer, D. (2004). Supercritical fluid extraction of quercetin from onion skins. Journal of Food Process Engineering, 27(1), 17-28. https:// doi.org/10.1111/j.1745-4530.2004.tb00620.x

Materska, M. (2008). Quercetin and its derivatives: chemical structure and bioactivity-a review. Polish journal o Food and Nutrition Sciences, 58(4), 407413

Medina-Torres, N., Ayora-Talavera, T., EspinosaAndrews, H., Sánchez-Contreras, A. and Pacheco, N. (2017). Ultrasound assisted extraction for the recovery of phenolic compounds from vegetable sources. Agronomy, 7(3), 47. https://doi.org/10.3390/ agronomy 7030047

Muñiz-Márquez, D.B., Martínez-Ávila, G.C., Wong-Paz, J.E., Belmares-Cerda, R., Rodríguez-Herrera, R. and Aguilar, C.N. (2013). Ultrasound-assisted extraction of phenolic compounds from Laurus nobilis L. and their antioxidant activity. Ultrasonics Sonochemistry, 20(5), 1149-1154. https:// doi.org/10.1016/j.ultsonch.2013.02.008

Nair, M.P., Kandaswami, C., Mahajan, S., Chadha, K.C., Chawda, R., Nair, H. and Schwartz, S.A. (2002). The flavonoid, quercetin, differentially regulates Th-1 (IFN $\gamma$ ) and Th-2 (IL4) cytokine gene expression by normal peripheral blood mononuclear cells. Biochimica et Biophysica Acta (BBA)Molecular Cell Research, 1593(1), 29-36. https:// doi.org/10.1016/S0167-4889(02)00328-2

Nam, M.W., Zhao, J., Lee, M.S., Jeong, J.H. and Lee, J. (2015). Enhanced extraction of bioactive natural products using tailor-made deep eutectic solvents: application to flavonoid extraction from Flossophorae. Green Chemistry, 17(3), 1718-1727. 
https://doi.org/10.1039/C4GC01556H

Rothwell, J.A., Perez-Jimenez, J., Neveu, V., MedinaRemon, A., M'Hiri, N., García-Lobato, P. and Scalbert, A. (2013). Phenol-Explorer 3.0: a major update of the Phenol-Explorer database to incorporate data on the effects of food processing on polyphenol content. Database, 2013, bat070. https:// doi.org/10.1093/database/bat070

Savic, I.M., Nikolic, V.D., Savic-Gajic, I.M., Nikolic, L.B., Moder, K. and Hopkins, M. (2016). Optimization of quercetin extraction from green tea (Camellia sinensis) using central composite design, and the pharmacological activity of the extract. Chemical and Biochemical Engineering Quarterly, 30(1), 103-115. https://doi.org/10.15255/ CABEQ.2015.2166

Wach, A., Pyrzyńska, K. and Biesaga, M. (2007). Quercetin content in some food and herbal samples. Food Chemistry, 100(2), 699-704. https:// doi.org/10.1016/j.foodchem.2005.10.028

Walle, T., Otake, Y., Walle, U.K. and Wilson, F.A. (2000). Quercetin glucosides are completely hydrolyzed in ileostomy patients before absorption. The Journal of Nutrition, 130(11), 26582661. https://doi.org/10.1093/jn/130.11.2658

Walle, T. (2004). Absorption and metabolism of flavonoids. Free radical biology and medicine, 36 (7), 829-837. https://doi.org/10.1016/ j.freeradbiomed.2004.01.002

Wiczkowski, W. and Piskuła, M.K. (2004). Food flavonoids. Polish Journal of Food and Nutrition Sciences, 13(Suppl. 1), 101-114.

Wiczkowski, W., Romaszko, J., Bucinski, A., SzawaraNowak, D., Honke, J., Zielinski, H. and Piskula, M.K. (2008). Quercetin from shallots (Allium cepa L. var. aggregatum) is more bioavailable than its glucosides. The Journal of Nutrition, 138(5), 885888. https://doi.org/10.1093/jn/138.5.885

Yan, Q.H., Yang, L. and Wei, Y.M. (2015). Optimization of Extraction Methods for Flavonoids in Onion by RP-HPLC-DAD. Journal of Liquid Chromatography and Related Technologies, 38(7), 769-773. https:// doi.org/10.1080/10826076.2014.968658

Zhao, M., Yang, B., Wang, J., Liu, Y., Yu, L. and Jiang, Y. (2007). Immunomodulatory and anticancer activities of flavonoids extracted from litchi (Litchi chinensis Sonn.) pericarp. International Immunopharmacology, 7(2),162-166. https:// doi.org/10.1016/j.intimp.2006.09.003 